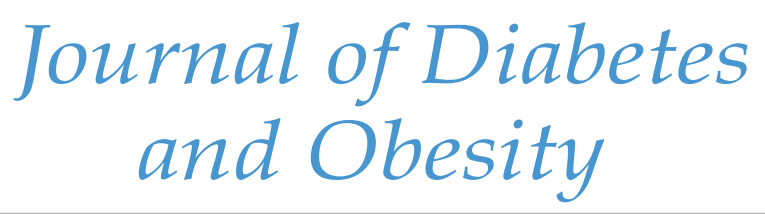

\title{
Addition of Metformin to Liraglutide, A GLP-1 Receptor Agonist, Improves Glycemic Control in Patients with Type 2 Diabetes Mellitus
}

\author{
Masao Toyoda $^{1 *}$, Masaaki Miyauchi ${ }^{1}$, Noriko Kaneyama ${ }^{1}$, Moritsugu Kimura ${ }^{1}$, Tomoya Umezono ${ }^{2}$, Dai- \\ suke Suzuki ${ }^{3}$, Masafumi Fukagawa ${ }^{1}$
}

${ }^{1}$ Division of Nephrology, Endocrinology and Metabolism, Department of Internal Medicine, Tokai University School of Medicine, Isehara, Kanagawa 259-1193, Japan

${ }^{2}$ Umezono Diabetes Clinic, Atsugi, Kanagawa 243-0018 Japan

${ }^{3}$ Suzuki Diabetes Clinic, Atsugi, Kanagawa 243-0035, Japan

"Corresponding author: Masao Toyoda, M.D., Ph.D., Division of Nephrology and Metabolism, Department of Internal Medicine, Tokai University School of Medicine, Isehara, Kanagawa 259-1193, Japan, Tel: +81-463-93-1121(ext. 2490); Fax: +81-46391-3350; E-mail: m-toyoda@is.icc.u-tokai.ac.jp

\begin{abstract}
Background: The maximum permissible dose of liraglutide, a GLP-1 receptor agonist, under the Japanese Heath Insurance system is $0.9 \mathrm{mg} /$ day. We determined the effects of adding metformin to liraglutide therapy in Japanese patients with type 2 diabetes. Material and Methods: This observational retrospective study included 47 patients with type 2 diabetes who were treated with liraglutide alone or in combination with sulfonylureas. Metformin was added at a dose ranging from 250 to $500 \mathrm{mg} /$ day based on inadequate glycemic control. Liraglutide and metformin doses were converted from $\mathrm{mg} /$ day to $\mathrm{mg} / \mathrm{kg}$ body weight/day before analysis of the correlation between the dose and changes in glycated hemoglobin (HbAlc) and body mass index (BMI).

Results: Both HbA1c and BMI decreased significantly after 24 weeks of the combination treatment. Mild gastrointestinal adverse events were reported by $21 \%$ of the patients. Only the dose of metformin, but not that of liraglutide, expressed in $\mathrm{mg} / \mathrm{kg}$ body weight was correlated significantly with decrease in HbAlc and BMI.

Conclusions: The addition of metformin to the maximum permissible dose of liraglutide helps secure glycemic control and reduce BMI in Japanese patients with type 2 diabetes who exhibit inadequate response to liraglutide.
\end{abstract}

Received date: January 08, 2017

Accepted date: February 06, 2017

Published date: February 11, 2017

Citation: Toyoda, M., et al. Addition of Metformin to Liraglutide, A GLP-1 Receptor Agonist, Improves Glycemic Control in Patients with Type 2 Diabetes Mellitus (2017) J diab Obes 4(1): 1- 6.

DOI: $10.15436 / 2376-0494.17 .1300$

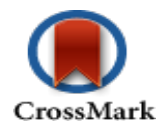

Keywords: Type 2 diabetes mellitus; Obesity; Metformin; GLP-1 receptor agonist; Body mass index

\section{Introduction}

Glucagon-like peptide-1 (GLP-1) has been reported in various basic and clinical studies to have diverse physiological effects, including but not limited to inducing glucose-dependent insulin secretion with consequent lowering of blood glucose levels, and suppression of both appetite and gastrointestinal peristalsis, leading to BMI decrease ${ }^{[1-3]}$.

Liraglutide, the first GLP-1 receptor agonist became available for clinical use under the Japanese Government Health Insurance scheme in 2010. However, the clinical indications re- garding insurance coverage have been more problematic than in Western countries. Namely, liraglutide is covered by the scheme only when it is used alone or in combination with sulfonylureas (SU) drugs. Thus, it is common to discontinue drug therapy other than SUs, when liraglutide is added to the treatment of patients with type 2 diabetes (T2DM), who are often treated with 3 or 4 oral antidiabetic medications. Occasionally, this results in cases where glycemic control is unaffected or worsens after changes in the medication regimen. Switching from insulin therapy to liraglutide has also been reportedly to cause severe hyperglyce$\operatorname{mia}^{[4,5]}$.

Copyrights: (C) 2017 Toyoda, M. This is an Open access article distributed under the terms of Creative Commons Attribution 4.0 International License. 
The mechanism of abnormal glucose metabolism in Japanese patients with T2DM is mainly impaired insulin secretion, where even moderate extent of insulin resistance may result in the development and progression of diabetes. This is in contrast to European and American patients with T2DM, in whom insulin resistance predominates ${ }^{[6]}$. However, recent reports have stated that the mean body mass index (BMI) of Japanese patients with T2DM has been increasing annually, and that there has been an increase in the number of cases of T2DM complicated by obesity with a BMI of $25 \mathrm{~kg} / \mathrm{m}^{2}$ or higher ${ }^{[7]}$. Metformin hydrochloride, which is recommended by the position statement of the American Diabetes Association (ADA)/European Association for the Study of Diabetes (EASD), is widely used even in Japan as the first choice therapy for patients with T2DM complicated with obesity because of its low cost, effects that are less likely to increase BMI, and enhancement of insulin sensitivity, among other advantages ${ }^{[8]}$.

From a similar clinical background, liraglutide was introduced for the treatment of T2DM, with the expectation of not only glycemic control but also a BMI decrease effect. However, the current use and dose ranges in Japan are limited to 0.9 $\mathrm{mg}$ /day, half of those allowed in Western countries. Instead, the Health Insurance scheme allows the concurrent use of SUs only, which can cause BMI increase. These regulations could limit the use of liraglutide for glycemic control and BMI control ${ }^{[9]}$. In fact, we reported recently that high BMI is an independent factor for discontinuation of liraglutide in Japanese patients with $\mathrm{T} 2 \mathrm{DM}$, in addition to long disease duration and history of using insulin ${ }^{[10]}$.

The indications for liraglutide use were, however; revised in August 2014. The new regulations allow the concurrent use of liraglutide with SUs, rapid-acting insulin secretagogues, $\alpha$-glucosidase inhibitors, insulin sensitizers, biguanides, and insulin preparations. European and US studies have reported that the rate of improvement to the combination of metformin and liraglutide in terms of glycated hemoglobin (HbAlc) level, BMI decrease, and avoidance of hypoglycemia is much higher than other therapeutic drugg ${ }^{[11,12]}$ suggesting that the two indices of HbA1c and BMI could potentially improve by the concurrent use of metformin and liraglutide in Japanese patients with T2DM. However, only a short period has passed since the new approval of liraglutide use in Japan, and thus there are only a few reports on its long-term ( 24 weeks) use.

The aim of the present study was to determine the effects of adding metformin to liraglutide therapy in Japanese patients with T2DM.

\section{Materials and Methods}

\section{Study design}

The subjects in this study included all 56 patients with T2DM who received outpatient treatment with liraglutide (0.9 mg/day) at our hospital between August 2012 and November 2014 , either as a monotherapy or in combination with SUs. Metformin was added to the above treatment at a daily dose of 250 - $500 \mathrm{mg}$. However, the dose was increased in some patients up to $2,250 \mathrm{mg} /$ day at the discretion of the attending physician. The adverse events were monitored and the decision to continue or discontinue liraglutide or metformin was also made by the attending physician. We investigated the effects of treatment on glycemic control, as indicated by HbAlc level and BMI from the time of registration (week 0) until week 24 of treatment. The doses of liraglutide and metformin were expressed relative to body weight before analyzing the correlation between treatment and changes in $\mathrm{HbA} 1 \mathrm{c}$ level and BMI. BMI $\left(\mathrm{kg} / \mathrm{m}^{2}\right)$, HbA1c level $(\%)$, systolic blood pressure $(\mathrm{mmHg})$, diastolic blood pressure $(\mathrm{mmHg})$ and other clinical data including blood biochemical examination data were recorded at baseline (immediately before start of metformin therapy), and changes in these variables were monitored during the treatment. HbAlc levels were measured according to the NGSP values and determined by high-performance liquid chromatography. We also recorded age, sex, and duration of diabetes from the medical records.

This study complies with the Declaration of Helsinki and with the Ethical Guidelines for Clinical Studies; consent was obtained from subjects who had received an explanation in writing. The study was carried out with the approval of the Institutional Review Board for Clinical Research, Tokai University Hospital (12R-004) and was registered with the University Hospital Medical Information Network (UMIN) clinical trial registry before the start of the study (ID: UMIN000009636).

\section{Statistics}

All clinical parameters, including $\mathrm{HbA1c}$ and BMI from baseline (week 0) to week 24 of treatment were expressed as mean $\pm \mathrm{SD}$. The Wilcoxon test was used for comparisons between two groups, and Spearman's rank correlation coefficient was used to analyze bivariate correlations. The Wilcoxon signed-rank test, a two-tailed hypothesis test, was used for comparisons between the time at registration (week 0) and week 24. Statistical significance was defined as $\mathrm{p}<0.05$, and a tendency was defined as $\mathrm{p}<0.1$.

The primary endpoints in this study were changes in $\mathrm{HbA} 1 \mathrm{c}$ and BMI. Improvement in HbA1c level was defined as a decrease in HbA1c level from treatment weeks 0 to 24, while improvement in BMI was defined as BMI decrease at treatment week 24 relative to baseline. All statistical analyses were performed using the JMP software (ver. 11.0.0, SAS Institute Inc. Cary, NC).

\section{Results}

\section{Subjects and baseline characteristics}

Of the 56 entry cases, 47 completed the 24 weeks of the combination therapy and served as the analysis subjects. The other 9 cases discontinued the treatment and were excluded from the analysis; 5 discontinued hospital visitation, 3 cases used other antidiabetic drugs such as insulin, and 1 case discontinued the treatment because of diarrhea and abdominal pain, which appeared after the introduction of metformin.

Table 1 summarizes the clinical background of the 47 subjects at study entry. The study included 29 men and 18 women, with a mean age of $57.6 \pm 11.4$ years. The mean BMI was $27.6 \pm 5.0 \mathrm{~kg} / \mathrm{m}^{2}$. HbAlc level at registration was $7.5 \pm 1.1 \%$, liraglutide dose was $0.9 \mathrm{mg} /$ day, and the dose expressed per $\mathrm{kg}$ body weight was $0.0130 \pm 0.0032 \mathrm{mg} / \mathrm{kg}$. 
Table 1: Patient background.

\begin{tabular}{|l|c|}
\hline Age & $57.6 \pm 11.4$ \\
\hline Sex (M/F) & $29 / 18$ \\
\hline Disease duration (years) & $9.2 \pm 5.0$ \\
\hline BMI (kg/m2) & $27.6 \pm 5.0$ \\
\hline Systolic blood pressure (mmHg) & $124.8 \pm 10.0$ \\
\hline Diastolic blood pressure (mmHg) & $78.6 \pm 8.9$ \\
\hline HbA1c (\%) & $7.5 \pm 1.1$ \\
\hline Fasting blood glucose (mg/dl) & $156.2 \pm 46.8$ \\
\hline C-peptide immunoreactivity (ng/ml) & $2.5 \pm 0.9$ \\
\hline Immunoreactive insulin ( $\boldsymbol{\mu U} / \mathbf{m l})$ & $13.2 \pm 9.2$ \\
\hline Aspartate transaminase (U/L) & $25.7 \pm 13.0$ \\
\hline Alanine transaminase (U/L) & $31.3 \pm 18.8$ \\
\hline Serum creatinine (mg/d) & $0.78 \pm 0.19$ \\
\hline Triglyceride (mg/dl) & $153.0 \pm 101.8$ \\
\hline Total cholesterol (mg/dl) & $189.6 \pm 35.1$ \\
\hline High-density lipoprotein (mg/d) & $62.2 \pm 16.3$ \\
\hline Low-density lipoprotein (mg/d) & $108.6 \pm 26.6$ \\
\hline Dose of liraglutide (mg/kg) & $0.0130 \pm 0.0032$ \\
\hline
\end{tabular}

Data are mean $\pm \mathrm{SD}$.

\section{Safety and changes in HbA1c and BMI}

The mean metformin dose expressed by body weight was $12.96 \pm 6.95 \mathrm{mg} / \mathrm{kg}$. HbA1c changed from $7.5 \pm 1.1 \%$ at baseline to $7.1 \pm 1.2 \%$ at 24 weeks after start of metformin ( $p<$ 0.001 ), and BMI decreased from $27.6 \pm 5.0$ at baseline to 27.1 $\pm 5.1 \mathrm{~kg} / \mathrm{m}^{2}$ at 24 weeks $(\mathrm{p}<0.005)$. A significant improvement was also noted in fasting blood glucose level, which decreased from $156.2 \pm 46.8$ to $142.7 \pm 42.7 \mathrm{mg} / \mathrm{dL}(\mathrm{p}<0.05$, Table 2$)$.

Table 2: Effects of 24-week combination therapy on various clinical parameters.

\begin{tabular}{|c|c|c|c|}
\hline & Baseline & 24 week & p-value \\
\hline BMI $\left(\mathrm{kg} / \mathrm{m}^{2}\right)$ & $27.6 \pm 5.0$ & $27.1 \pm 5.1$ & $<0.005$ \\
\hline $\begin{array}{l}\text { Systolic blood pressure } \\
(\mathrm{mmHg})\end{array}$ & $124.8 \pm 10.0$ & $122.1 \pm 12.0$ & NS \\
\hline $\begin{array}{l}\text { Diastolic blood pressure } \\
\text { (mmHg) }\end{array}$ & $78.6 \pm 8.9$ & $78.3 \pm 10.8$ & NS \\
\hline HbA1c (\%) & $7.5 \pm 1.1$ & $7.1 \pm 1.2$ & $<0.001$ \\
\hline $\begin{array}{l}\text { Fasting blood glucose (mg/ } \\
\text { dl) }\end{array}$ & $156.2 \pm 46.8$ & $142.7 \pm 42.7$ & $<0.05$ \\
\hline $\begin{array}{l}\text { Aspartate transaminase } \\
\text { (U/L) }\end{array}$ & $25.7 \pm 13.0$ & $24.6 \pm 9.6$ & NS \\
\hline Alanine transaminase $(\mathrm{U} / \mathrm{L})$ & $31.3 \pm 18.8$ & $29.4 \pm 15.8$ & NS \\
\hline Serum creatinine (mg/dl) & $0.78 \pm 0.19$ & $0.76 \pm 0.19$ & NS \\
\hline Triglyceride (mg/dl) & $153.0 \pm 101.8$ & $151.0 \pm 80.3$ & NS \\
\hline Total cholesterol (mg/dl) & $189.6 \pm 35.1$ & $187.6 \pm 33.7$ & NS \\
\hline $\begin{array}{l}\text { High-density lipoprotein } \\
\text { (mg/dl) }\end{array}$ & $62.2 \pm 16.3$ & $60.4 \pm 13.9$ & NS \\
\hline $\begin{array}{l}\text { Low-density lipoprotein } \\
\text { (mg/dl) }\end{array}$ & $108.6 \pm 26.6$ & $111.1 \pm 27.0$ & NS \\
\hline Dose of liraglutide (mg/kg) & $\begin{array}{l}0.0130 \pm \\
0.0032\end{array}$ & $\begin{array}{l}0.0132 \pm \\
0.0034\end{array}$ & $<0.001$ \\
\hline Dose of metformin (mg/kg) & $12.96 \pm 6.95$ & $13.26 \pm 7.24$ & $<0.0001$ \\
\hline
\end{tabular}

Data are mean $\pm \mathrm{SD}$, NS: not significant.
With regard to safety, 10 out of the 47 cases experienced some adverse events, including diarrhea $(n=3)$, constipation $(\mathrm{n}=2)$, abdominal pain $(\mathrm{n}=2)$, and anorexia $(\mathrm{n}=1)$, i.e., 8 cases of gastrointestinal complications. However, all were mild symptoms, and with the exception of 1 case in which the metformin dose had to be reduced, all patients were able to continue the treatment to the end of the 24 weeks through the avoidance of further increase in dosage. One other case experienced vertigo, but none developed hypoglycemia, other than in 1 individual who developed hypoglycemia after consuming a large amount of alcohol.

\section{Effects according to sex, BMI and HbA1c}

Table 3 shows the results of comparison of background and clinical parameters between the groups. The mean baseline doses of liraglutide and metformin dosage were $0.0118 \pm 0.0023$ and $11.97 \pm 7.75 \mathrm{mg} / \mathrm{kg}$, respectively, for male, and $0.0149 \pm$ 0.0035 and $14.54 \pm 5.22 \mathrm{mg} / \mathrm{kg}$, respectively, for female; the dose by $\mathrm{kg}$ body weight was significantly larger in female than male. Both the baseline BMI and HbAlc were similar in male and female; however, female showed a significantly greater change in BMI after 24 weeks $(p<0.05)$ while HbA1c did not change significantly in both sexes.

Comparison according to BMI decrease/increase showed that the mean baseline doses of liraglutide and metformin were $0.0133 \pm 0.0033$ and $14.54 \pm 7.46 \mathrm{mg} / \mathrm{kg}$, respectively, in the BMI decrease group, and $0.0122 \pm 0.0028$ and 9.57 $\pm 4.14 \mathrm{mg} / \mathrm{kg}$, respectively, in the BMI increase group; a significantly larger dose of metformin was used in the BMI decrease group $(\mathrm{p}<0.05, \mathrm{p}<0.01)$. There were no differences between the two BMI groups with respect to BMI and $\mathrm{HbA} 1 \mathrm{c}$ at baseline; however, the change in HbA1c ( $\triangle \mathrm{HbA} 1 \mathrm{c})$ after 24 weeks was significantly greater in the BMI decrease group $(\mathrm{p}<0.05)$.

Table 3: Comparisons based on sex and changes in BMI and HbAlc.

\begin{tabular}{|c|c|c|c|}
\hline $\begin{array}{l}\text { Sex-based } \\
\text { comparison }\end{array}$ & $\begin{array}{c}\text { Male } \\
(n=29)\end{array}$ & $\begin{array}{l}\text { Female } \\
(n=18)\end{array}$ & p-value \\
\hline BMI $\left(\mathrm{kg} / \mathrm{m}^{2}\right)$ & $27.4 \pm 4.4$ & $26.8 \pm 6.0$ & NS \\
\hline HbA1c (\%) & $7.35 \pm 1.11$ & $7.66 \pm 1.01$ & NS \\
\hline $\begin{array}{l}\text { Liraglutide } 0 \\
\text { wk (mg/kg) }\end{array}$ & $0.0118 \pm 0.0023$ & $0.0149 \pm 0.0035$ & $<0.0005$ \\
\hline $\begin{array}{l}\text { Liraglutide } 24 \\
\text { wks (mg/kg) }\end{array}$ & $0.0119 \pm 0.0023$ & $0.0153 \pm 0.0038$ & $<0.0005$ \\
\hline $\begin{array}{l}\text { Metformin } 0 \\
\text { wk (mg/kg) }\end{array}$ & $11.97 \pm 7.75$ & $14.54 \pm 5.22$ & $<0.05$ \\
\hline $\begin{array}{l}\text { Metformin } 24 \\
\text { wks (mg/kg) }\end{array}$ & $12.19 \pm 8.04$ & $15.00 \pm 5.50$ & $<0.05$ \\
\hline$\triangle \mathrm{BMI}$ & $0.3 \pm 1.0$ & $0.7 \pm 0.5$ & $<0.05$ \\
\hline$\Delta H b A 1 c$ & $0.1 \pm 0.7$ & $0.6 \pm 0.7$ & $\mathrm{NS}$ \\
\hline
\end{tabular}


Efficacy of Metformin and Liraglutide Therapy

\begin{tabular}{|l|l|l|l|}
\hline \hline $\begin{array}{l}\text { BMI-based } \\
\text { comparison }\end{array}$ & $\begin{array}{l}\text { BMI decrease } \\
(\mathbf{n = 3 2 )}\end{array}$ & $\begin{array}{l}\text { BMI increase } \\
(\mathbf{n}=\mathbf{1 5})\end{array}$ & p-value \\
\hline BMI(kg/m $\mathbf{~})$ & $26.9 \pm 4.3$ & $27.7 \pm 6.4$ & $\mathrm{NS}$ \\
\hline HbA1c (\%) & $7.58 \pm 1.02$ & $7.23 \pm 1.17$ & $\mathrm{NS}$ \\
\hline $\begin{array}{l}\text { Liraglutide0 } \\
\text { wk (mg/kg) }\end{array}$ & $0.0133 \pm 0.0033$ & $0.0122 \pm 0.0028$ & $\mathrm{NS}$ \\
\hline $\begin{array}{l}\text { Liraglutide24 } \\
\text { wks (mg/kg) }\end{array}$ & $0.0138 \pm 0.0035$ & $0.0120 \pm 0.0028$ & $\mathrm{NS}(<0.1)$ \\
\hline $\begin{array}{l}\text { Metformin 0 } \\
\text { wk (mg/kg) }\end{array}$ & $14.54 \pm 7.46$ & $9.57 \pm 4.14$ & $<0.05$ \\
\hline $\begin{array}{l}\text { Metformin 24 } \\
\text { wks (mg/kg) }\end{array}$ & $15.04 \pm 7.74$ & $9.47 \pm 4.15$ & $<0.01$ \\
\hline $\mathbf{\Delta B M I}$ & $0.8 \pm 0.7$ & $-0.4 \pm 0.4$ & Not Done \\
\hline $\mathbf{\Delta H b A 1 c}$ & $0.5 \pm 0.7$ & $-0.1 \pm 0.6$ & $<0.05$ \\
\hline
\end{tabular}

\begin{tabular}{|c|c|c|c|}
\hline $\begin{array}{l}\text { HbA1c-based } \\
\text { comparison }\end{array}$ & $\begin{array}{l}\text { HbA1c improve } \\
(n=35)\end{array}$ & $\begin{array}{l}\text { HbA1c not im- } \\
\text { prove }(n=12)\end{array}$ & p-value \\
\hline BMI $\left(\mathrm{kg} / \mathrm{m}^{2}\right)$ & $26.9 \pm 5.0$ & $28.0 \pm 4.9$ & NS \\
\hline HbA1c (\%) & $7.52 \pm 0.78$ & $7.32 \pm 1.70$ & $\mathrm{NS}(<0.1)$ \\
\hline $\begin{array}{l}\text { Liraglutide0 } \\
\text { wk (mg/kg) }\end{array}$ & $0.0132 \pm 0.0030$ & $0.0123 \pm 0.0036$ & NS \\
\hline $\begin{array}{l}\text { Liraglutide24 } \\
\text { wks (mg/kg) }\end{array}$ & $0.0135 \pm 0.0032$ & $0.0124 \pm 0.0040$ & $\mathrm{NS}(<0.1)$ \\
\hline $\begin{array}{l}\text { Metformin } 0 \\
\text { wk (mg/kg) }\end{array}$ & $13.11 \pm 6.99$ & $12.52 \pm 7.11$ & NS \\
\hline $\begin{array}{l}\text { Metformin } 24 \\
\text { wks (mg/kg) }\end{array}$ & $13.44 \pm 7.22$ & $12.74 \pm 7.60$ & NS \\
\hline$\Delta \mathrm{BMI}$ & $0.6 \pm 0.8$ & $0.0 \pm 0.9$ & $\mathrm{NS}(<0.1)$ \\
\hline$\Delta \mathrm{HbA1c}$ & $0.6 \pm 0.5$ & $-0.5 \pm 0.6$ & Not Done \\
\hline
\end{tabular}

Data are mean \pm SD, NS: not significant.

The mean baseline doses of liraglutide and metformin were $0.0132 \pm 0.0030$ and $13.11 \pm 6.99 \mathrm{mg} / \mathrm{kg}$, respectively, in the HbA1c improvement group, and $0.0123 \pm 0.0036$ and 12.52 $\pm 7.11 \mathrm{mg} / \mathrm{kg}$, respectively, in the HbAlc worsening group; no significant difference in the doses was observed between the two groups. Baseline BMI and $\mathrm{HbAlc}$ were similar in the two groups, as was the change in BMI $(\triangle \mathrm{BMI})$ at 24 weeks.

Table 4: Comparison of patients treated with low and high dose of liraglutide using a cutoff value of $0.013 \mathrm{mg} / \mathrm{kg}$.

\begin{tabular}{|l|l|l|l|}
\hline & High-dose group & Low-dose group & p-value \\
\hline $\mathbf{n}$ & 21 & 26 & \\
\hline BMI (kg/m $\mathbf{2})$ & $23.6 \pm 2.5$ & $30.1 \pm 4.6$ & $<0.0001$ \\
\hline HbA1c (\%) & $7.34 \pm 0.76$ & $7.58 \pm 1.27$ & NS \\
\hline $\begin{array}{l}\text { Liraglutide } \\
\text { (mg/kg) }\end{array}$ & $0.0157 \pm 0.0025$ & $0.0108 \pm 0.0014$ & Not done \\
\hline $\begin{array}{l}\text { Metformin } \\
\text { (mg/kg) }\end{array}$ & $14.78 \pm 8.05$ & $11.49 \pm 5.64$ & NS \\
\hline MBMI & $0.5 \pm 0.6$ & $0.4 \pm 1.0$ & NS \\
\hline MHbA1c & $0.6 \pm 0.7$ & $0.1 \pm 0.7$ & NS $(<0.1)$ \\
\hline
\end{tabular}

Data are mean $\pm \mathrm{SD}$, NS: not significant.

\section{Clinical effects of liraglutide according to baseline BMI}

To study how the clinical effects of metformin are influenced by the dose of liraglutide, we divided the subjects into the high liraglutide dose group $(\geq 0.0130 \mathrm{mg} / \mathrm{kg})$ and low liraglutide dose group $(<0.0130 \mathrm{mg} / \mathrm{kg})$. The selected cutoff value represented the mean dose by body weight of $0.0130 \pm 0.0032 \mathrm{mg} / \mathrm{kg}$. We compared the effects of treatment on HbA1c and BMI (Table 4). Although the dose of metformin did not change significantly, $\Delta \mathrm{HbA} 1 \mathrm{c}$ showed tendency for improvement at week 24 in the $\geq$ $0.0130 \mathrm{mg} / \mathrm{kg}$ liraglutide group $(\mathrm{p}<0.1)$. This finding suggests that liraglutide dose at or above certain concentration is needed for an $\mathrm{HbA1c}$-improvement effect when used concurrently with metformin.
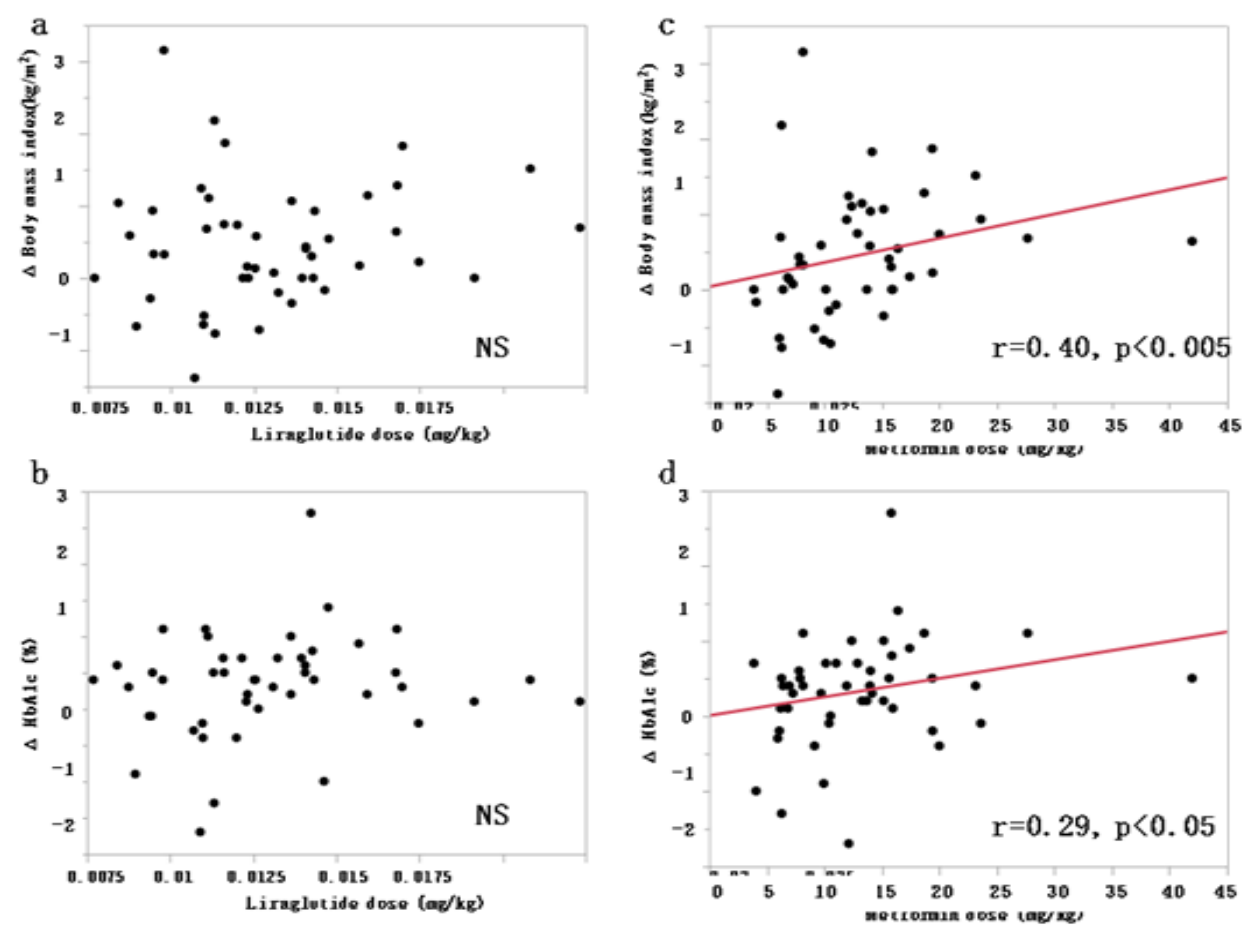

Figure 1: Correlation between liraglutide dose by body weight and $\triangle \mathrm{BMI}$ (a) and $\Delta \mathrm{HbA} 1 \mathrm{c}$ (b) Correlation between metformin dose by body weight and $\triangle \mathrm{BMI}(\mathrm{c})$ and $\triangle \mathrm{HbA} 1 \mathrm{c}(\mathrm{d})$ 


\section{Correlation between liraglutide and metformin dose, and changes in HbA1c and BMI}

Figure 1 shows results of analysis of the relationships between liraglutide and metformin doses per $\mathrm{kg}$ body weight, and $\mathrm{HbA} 1 \mathrm{c}$ improvement and BMI decrease. There were no significant correlations between liraglutide dose and $\triangle \mathrm{BMI}$ and $\triangle \mathrm{HbA} 1 \mathrm{c}$. In comparison, metformin dose correlated significantly with $\triangle B M I(p<0.005)$ and $\Delta H b A 1 c(p<0.05)$. These results indicate that the addition of metformin to $0.9 \mathrm{mg}$ /day liraglutide has a favorable effect on both HbA1c and BMI.

Finally, we studied the dose-dependent effects of adding metformin to liraglutide, after dividing the subjects into four groups (based on the quartiles of metformin dose by body weight). Specifically, we analyzed the extent of changes in BMI and $\mathrm{HbAlc}$ after 24 weeks of treatment. The results showed that the addition of metformin at a dose of $\geq 12.12 \mathrm{mg} / \mathrm{kg}$, but not lower doses, was associated with significant BMI decrease and improvement in HbA1c (Figure 2).

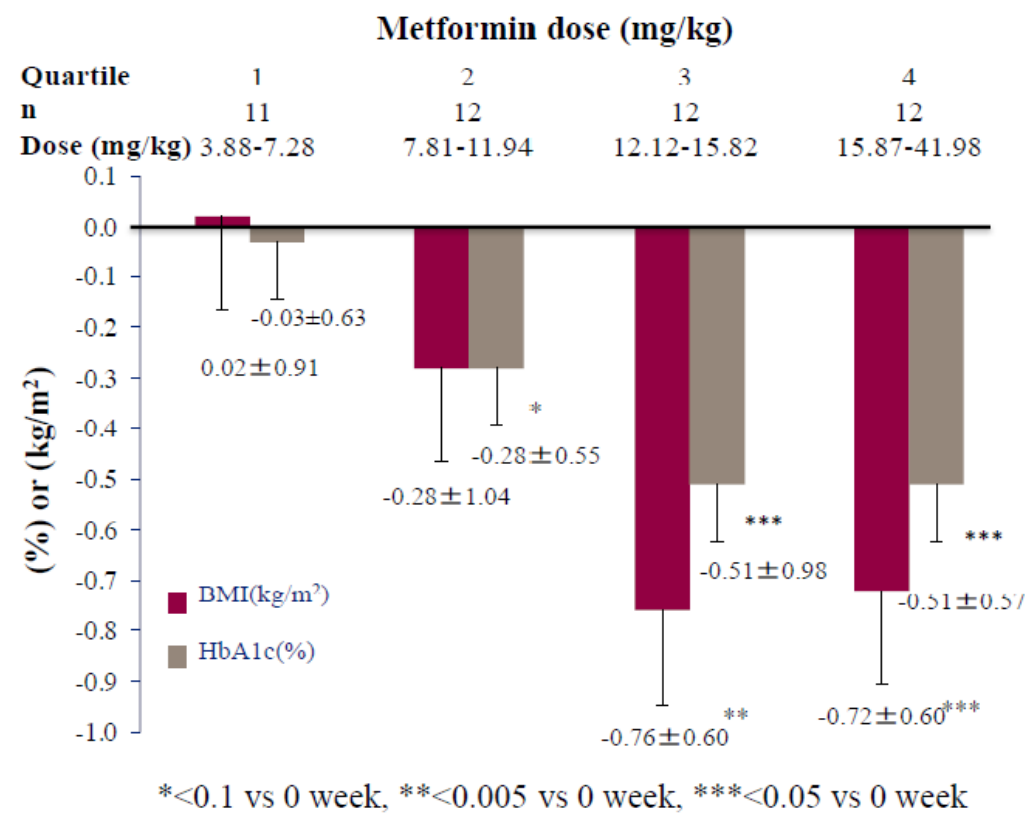

Figure 2: Rates of reduction of $\mathrm{HbA1c}$ and BMI after 24 weeks treatment with the combination therapy of liraglutide plus metformin according to metformin dose by body weight.

\section{Discussion}

Our study investigated the usefulness, as expressed by changes in HbAlc and BMI, of adding metformin to $0.9 \mathrm{mg} /$ day liraglutide for the treatment of patients with T2DM. The results based on analysis of data of 47 patients demonstrated that both $\mathrm{HbA} 1 \mathrm{c}$ and BMI were significantly lower at the end of 24 week of treatment, confirming that the addition of metformin improves the outcome of inadequate treatment with liraglutide (0.9 mg/day).

Several studies and clinical trials have reported the clinical usefulness of concurrent use of various GLP-1 receptor agonists with metformin ${ }^{[11-14]}$ and those GLP-1 receptor agonists are useful in Japanese patients with T2DM. However, in these clinical trials, the subjects were T2DM patients in whom treatment with metformin did not achieve adequate glycemic control ${ }^{[15]}$. To our knowledge, the present study is the first to demonstrate that the combination of metformin and GLP-1 receptor agonists improves $\mathrm{HbAlc}$ and enhances BMI decrease in patients with T2DM. Thus, we recommend the addition of metformin to patients with T2DM in whom treatment with GLP-1 receptor agonists does not provide adequate glycemic or BMI control.

Liraglutide is considered to enhance BMI decrease through its action peripherally by suppression of gastric peristalsis or centrally through its actions on the central nervous system, including the satiety and appetite centers ${ }^{[3-6,19]}$. The daily dose of liraglutide used in western countries is up to $1.8 \mathrm{mg}$ for T2DM and $3.0 \mathrm{mg}$ for obesity, whereas in Japan, the approved dose for
$\mathrm{T} 2 \mathrm{DM}$ is only $50 \%$ of that used in western countries ${ }^{[20-22]}$. It is possible that the high rate of inadequate control of hyperglycemia in liraglutide-treated Japanese patients with T2DM is due to the use of suboptimal dose of liraglutide. The possibility that the approved dose of liraglutide in Japan is not clinically adequate is also inferred from the fact that there was no correlation between liraglutide dose by body weight and $\triangle \mathrm{BMI}$ or $\triangle \mathrm{HbA} 1 \mathrm{c}$ (Figure $1)$. In addition, from our results, the significant correlations between the combination of liraglutide and metformin with BMI, $\triangle \mathrm{BMI}$ and $\triangle \mathrm{HbA} 1 \mathrm{c}$ strongly imply that metformin needs to be added to the treatment regimen in patients with poor response to liraglutide. Therefore, there may be a need to at least expand the indications to allow the use of liraglutide at $1.8 \mathrm{mg}$ /day or to allow the concurrent use of metformin for Japanese patients with T2DM. In addition, the effective dose of metformin for BMI control and glycemic control estimated from the present study is at least $12.12 \mathrm{mg} / \mathrm{kg}$ (Figure 2). Further larger studies are needed to confirm the optimal dose of metformin required for glycemic control and BMI decrease.

Our study showed none of the patients discontinued the medications during the trial period ( 24 weeks) due to adverse events, suggesting favorable drug tolerance. Analysis data of all of patients showed significant improvements in HbAlc and BMI. It is noteworthy that the gastrointestinal symptoms occurred in patients who did not experience problematic symptoms during the use of liraglutide monotherapy before the start of the present study, suggesting that these gastrointestinal symptoms were related to metformin use. Based on this conclusion, we rec- 
ommend gradual escalation of metformin dose while monitoring the patient for the appearance of gastrointestinal or related symptoms at every visit, in terms of both adherence and safety. The present study has certain limitations. First, our study was a single-arm study. Second, examination of the effects of the combination therapy was limited to 24 weeks only. A multicenter long-term randomized controlled trial of large number of patients is needed to confirm the present results. Similarly, a prospective study of a large number of patients is needed to determine the true rate of adverse events.

In conclusion, we have demonstrated in the present study that the addition of metformin to liraglutide therapy provides better glycemic control and results in significant BMI decrease in Japanese patients with T2DM. These results may call for re-adjustment of the optimal dose of liraglutide for Japanese patients with T2DM to ensure adequate glycemic and BMI control.

\section{Acknowledgment}

This study was sponsored by the Division of Nephrology, Endocrinology and Metabolism, Department of Internal Medicine (Grant No. 13F188139), Tokai University School of Medicine, Japan.

Conflict of Interest: The authors declare that they have no conflict of interest.

\section{References}

1. Seino, Y., Yabe, D. Glucose-dependent insulinotropic polypeptide and glucagon-like peptide-1: Incretin actions beyond the pancreas. (2013) J Diabetes Investiq 4(2): S108-S130.

2. Drucker, D.J. Incretin action in the pancreas: potential promise, possible perils, and pathological pitfalls. (2013) Diabetes 62(10): S3316-S3323.

3. Van, Bloemendaal, L., Ten, Kulve, J.S., la, Fleur, S.E., et al. Effects of glucagon-like peptide 1 on appetite and body weight: focus on the CNS. (2014) J Endocrinol 221(1): T1-16.

4. Usui, R., Yabe, D., Kuwata, H., et al. Retrospective analysis of safety and efficacy of insulin-to-liraglutide switch in Japanese type 2 diabetes: A caution against inappropriate use in patients with reduced $\beta$-cell function. (2013) J Diabetes Investiq 4(6): S585-S594.

5. Kawata, T., Kanamori, A., Kubota, A., et al. Is a switch from insulin therapy to liraglutide possible in Japanese type 2 diabetes mellitus patients (2014) J Clin Med Res 6(2): S138-S144.

6. Yabe, D., Seino, Y., Fukushima, M., et al. $\beta$ cell dysfunction versus insulin resistance in the pathogenesis of type 2 diabetes in East Asians. (2015) Curr Diab Rep 15(6): S602.

7. Kushiyama, A., Yoshida, Y., Kikuchi, T., et al. Twenty-year trend of increasing obesity in young patients with poorly controlled type 2 diabetes at first diagnosis in urban Japan. (2013) J Diabetes Investiq 4(6): S540-S545.

8. Sumitani, S., Morita, S., Utsu, Y., et al. Effectiveness of metformin and lifestyle interventions as an initial treatment in Japanese patients with newly diagnosed type 2 diabetes: a prospective observational study. (2012) J Med Invest 59(1-2): S166-S173.

9. Ito, D., Iuchi, T., Kurihara, S., et al. Efficacy and clinical characteristics of liraglutide in Japanese patients with type 2 diabetes. (2015) J Clin Med Res 7(9): S694-S699.

10. Toyoda, M., Yokoyama, H., Abe, K., et al. Predictors of response to liraglutide in Japanese type 2 diabetes. (2014) Diabetes Res Clin Pract 106(3): S451-S457.

11. Pratley, R., Nauck, M., Bailey, T., et al. One year of liraglutide treatment offers sustained and more effective glycaemic control and weight reduction compared with sitagliptin, both in combination with metformin, in patients with type 2 diabetes: a randomised, parallel-group, open-label trial. (2011) Int J Clin Pract 65(4): S397-S407.

12. Nauck, M., Frid, A., Hermansen, K., et al. Long-term efficacy and safety comparison of liraglutide, glimepiride and placebo, all in combination with metformin in type 2 diabetes: 2-year results from the LEAD-2 study. (2013) Diabetes Obes Metab 15(3): S204-S212.

13. Gallwitz, B., Guzman, J., Dotta, F., et al. Exenatide twice daily versus glimepiride for prevention of glycaemic deterioration in patients with type 2 diabetes with metformin failure (EUREXA): an open-label randomised controlled trial. (2012) Lancet 379(9833): S2270-S2278.

14. Pratley, R.E., Nauck, M., Bailey, T., et al. Liraglutide versus sitagliptin for patients with type 2 diabetes who did not have adequate glycaemic control with metformin: a 26-week, randomised, parallel-group, open-label trial. (2010) Lancet 375(9724): S1447-S1456.

15. Kaku, K., Kiyosue, A., Ono, Y., et al. Liraglutide is effective and well tolerated in combination with an oral antidiabetic drug in Japanese patients with type 2 diabetes: A randomized, 52-week, open-label, parallel-group trial. (2016) J Diabetes Investiq 7(1): S76-S84.

16. Punjabi, M., Arnold, M., Geary, N., et al. Peripheral glucagon-like peptide-1 (GLP-1) and satiation. (2011) Physiol Behav 105(1): S71-S76. 17. Meier, J.J. GLP-1 receptor agonists for individualized treatment of type 2 diabetes mellitus. (2012) Nat Rev Endocrinol 8(12): S728-S742. 18. Dailey, M.J., Moran, T.H. Glucagon-like peptide 1 and appetite. (2013) Trends Endocrinol Metab 24(2): S85-S91.

19. Secher, A., Jelsing, J., Baquero, A.F., et al. The arcuate nucleus mediates GLP-1 receptor agonist liraglutide-dependent weight loss. (2014) J Clin Invest 124(10): S4473-S1488.

20. Davies, M.J., Bergenstal, R., Bode, B., et al. Efficacy of liraglutide for weight loss among patients with type 2 diabetes: the SCALE diabetes randomized clinical trial. (2015) JAMA 314(7): S687-S699.

21. Pi-Sunyer, X., Astrup, A., Fujioka, K., et al. A randomized, controlled trial of $3.0 \mathrm{mg}$ of liraglutide in weight management. (2015) N Engl J Med 373(1): S11-S22.

22. Wilding, J.P., Overgaard, R.V., Jacobsen, LV., et al. Exposure-response analyses of liraglutide $3.0 \mathrm{mg}$ for weight management. (2016) Diabetes Obes Metab 18(5): S491-S499.
Ommega Online Publishers

Journal Title: Journal of Diabetes and Obesity (JDO)

Journal Short Name: J diabetes Obes
Journal ISSN: 2356-0494

E-mail: diabetes@ommegaonline.com

Website: www.ommegaonline.org 